\title{
Desert Densities Sensing Atmospheric and Territorial Shifts in High-Density Desert Cities
}

\author{
ERSELA KRIPA
}

Texas Tech University

Dust surrounds us, saturating our bodies, cities, and landscapes with a nearly imperceptible airborne geology. Accelerating transcontinental migrations of airborne particulate in the US/Mexico borderland forge shifting binational territories, fluidly permeating boundaries between otherwise distinct nations, jurisdictions, and organisms. The shared geological, biological, and cultural material carried in the dust indexes reciprocal anthropogenic transformations, initiates unseen interdependencies, and has the potential to bind emerging, as-yet unaware constituencies in the region.

\section{NEPHELOMETRY}

Climate change has enacted wide-scale desertification across the world's dryland areas, mobilizing unprecedented climate migration from arid peripheries to urban centers. As a result, explosive growth and shifting sands combine to host a growing and diverse catalog of desert cities - high-density urban environments in remote areas - supporting large populations despite scarce and depleting resources. These unexpected and anomalous urbanisms face unique challenges, as both public infrastructures and private developments threaten to exhaust limited water supplies and degrade urban land, creating hazardous environmental air quality, the agent of which is dust.

A precise measurement of the airborne particulate matter, which inhabits the air of desert cities, has the potential to map with specificity sites of dust origins (figure 4), and by extension, areas of infrastructural degradation and environmental neglect. Nephelometry is a dust-sensing project, which operates at local and global scales by mapping dust trajectories across the binational region of El Paso and Ciudad Juarez. The project of measuring and mapping dust transmission is a design exercise to develop a toolset that renders visible specific urban and infrastructural issues shared by similar contexts globally. The process mines hyperlocal data towards a forensic material and geospatial investigation of the densifying desert cities on the U.S. - Mexico border, and indexes shifting urban and geological territories to forecast sites and strategies for improvement in this growing crisis. Access to information is empowering. In the El Paso-Ciudad Juarez region, high levels of air pollution inhabit people's bodies, yet they do not have a way to understand the contents of the air they breathe. By locating and cataloguing dust production sites, trajectories, and settlement, the visualizations can both predict future conditions while providing data that empowers citizens to demand change from their local governance. Nephelometry grounds the forensic project locally while catalyzing a comparative analysis of emerging, high-density desert cities of representative sites and territories. The deployment of a series of environmental sensors is used to produce original, empirical metrics and maps for a specific regional case-study. The case-study reveals the impact of population growth on urban land degradation, environmental air quality, and public health in the binational El Paso - Ciudad Juárez metroplex, a growing region of millions in the midst of the desertifying Chihuahuan Desert. The current phase of the graphic atlas and interactive geospatial databases (figures 2 and 3), integrate geological and topographic information with dust readings from geolocated dust sensors. Acting as the first phase of a multi-stage project, the current visualizations will receive desertification metrics, climate migration, urban population, and urban density statistics, to visualize and describe previously elusive intersections and interdependencies between desert geographies and urban growth.

\section{DUST AS VECTOR}

Desert cities are defined by their thick dusty air ${ }^{1}$ both in the imaginary of windy stories, and in the realities of their inhabitants' daily lives. As climate change continues to push an increasing number of cities towards desertification, the tools of the designer must continue to diversify and look both forensically at the near past and towards a near future. Enlisting information at the scale of the territory and inflecting it with the layers of localized jurisdictional, regulatory, cultural, and economic boundaries allows for surprisingly precise urban analysis and therefore design strategies. In Nephelometry, spread across the binational region, singular dust sensors measure unique air quality conditions while following regional weather patterns. Dust Transfer Corridor Maps (figure 5) depict a cohesively unified air mass above a divided territory, where, although unique occurrences register local infrastructural deterioration, the collective wind trajectory transfers dust continuously across the U.S. Mexico border in a swirling defiance of air quality regulations. The maps attempt to deepen the understanding of untold impacts of airborne particulate on the future of cities and their inhabitants. They serve as a basis to further expand the trajectory of the research, by connecting previous and ongoing geospecific studies with global trends in desertifying communities and high-density desert cities. Carrying direct resemblance to weather maps (figures 2 and 3 ), the visualization method aims to highlight gaps in the public record to 


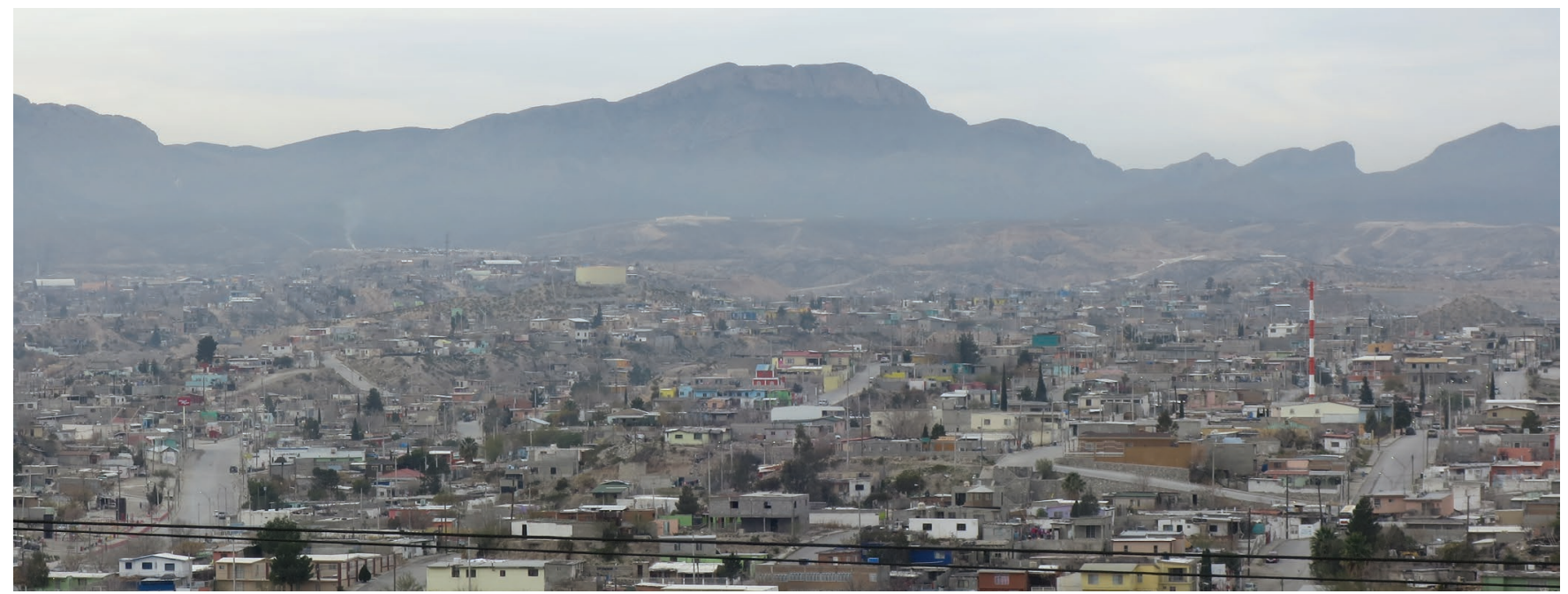

Figure 1. Dust trapped in the temperature inversion layer in Ciudad Juarez, creating a dust cloud. Copyright: Ersela Kripa.

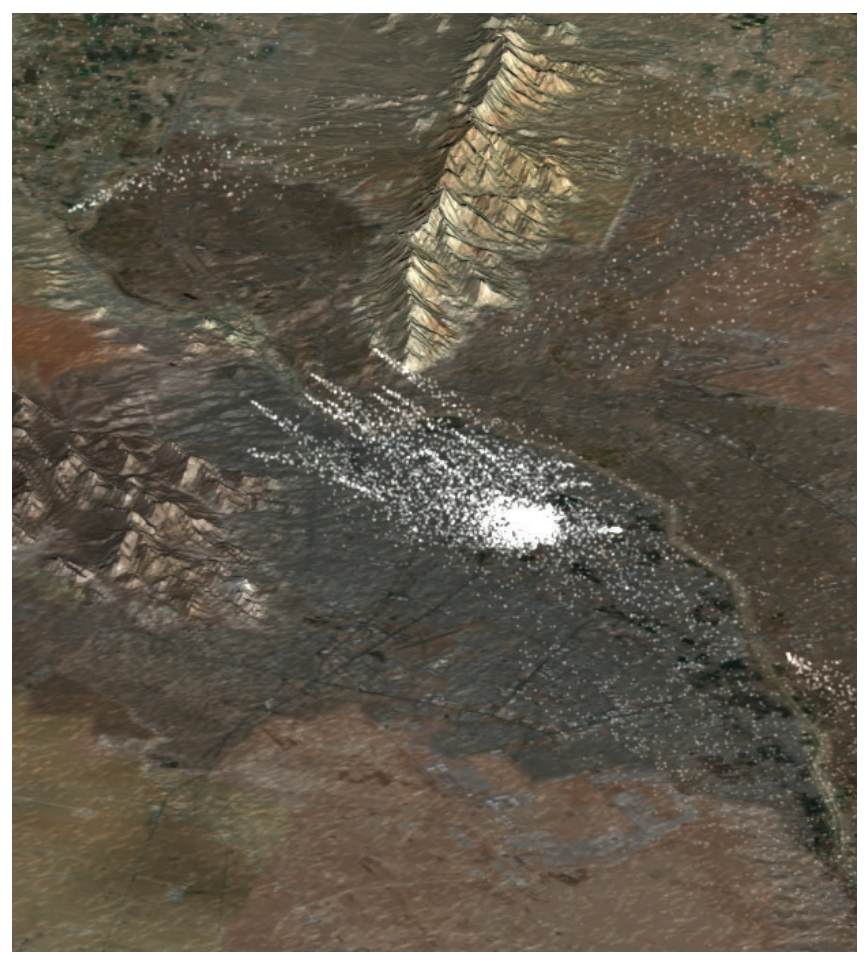

Figure 2. Dust sensor data visualization across the U.S. - Mexico Border. Copyright AGENCY Architecture LLC.

expose governmental neglect in the dense desert urbanisms of El Paso and Ciudad Juarez. By considering airborne particulate as the primary vector which shapes these geographies, the drawings can be used as proof of the negative impacts of unchecked development in underserved communities and general public health.

\section{DUST IN THE BORDERLANDS}

Dust surrounds us, saturating our bodies, cities, and landscapes with a nearly imperceptible airborne geology. ${ }^{2}$

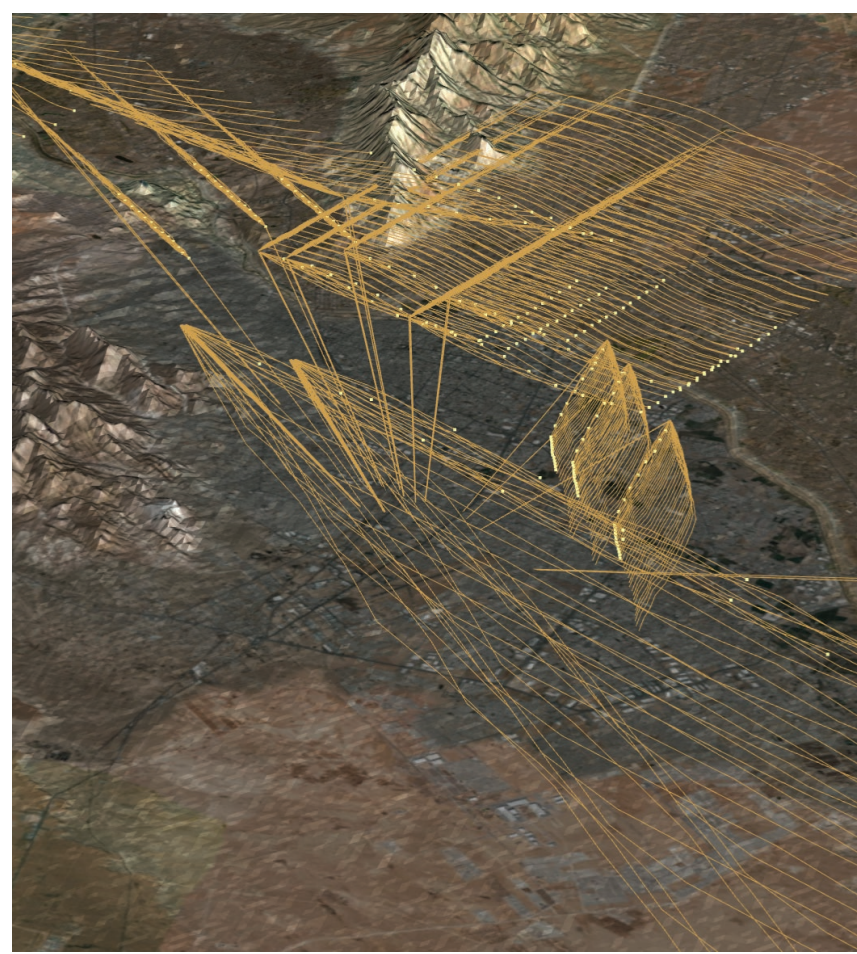

Figure 3. Dust sensor data visualization as vectors across the U.S. - Mexico Border. Copyright AGENCY Architecture LLC.

Accelerating transcontinental migration of airborne particulate in the US/Mexico borderland forges new and shifting binational territories, fluidly permeating boundaries between otherwise distinct nations, jurisdictions, and organisms. The shared geological, biological, and cultural material carried on the dust indexes reciprocal anthropogenic transformations, initiates unseen interdependencies, and has the potential to bind emerging, as-yet unaware constituencies in the region. The erosive eolian landscapes of the Chihuahuan Desert are the direct result of unique anthropogenic activity, 


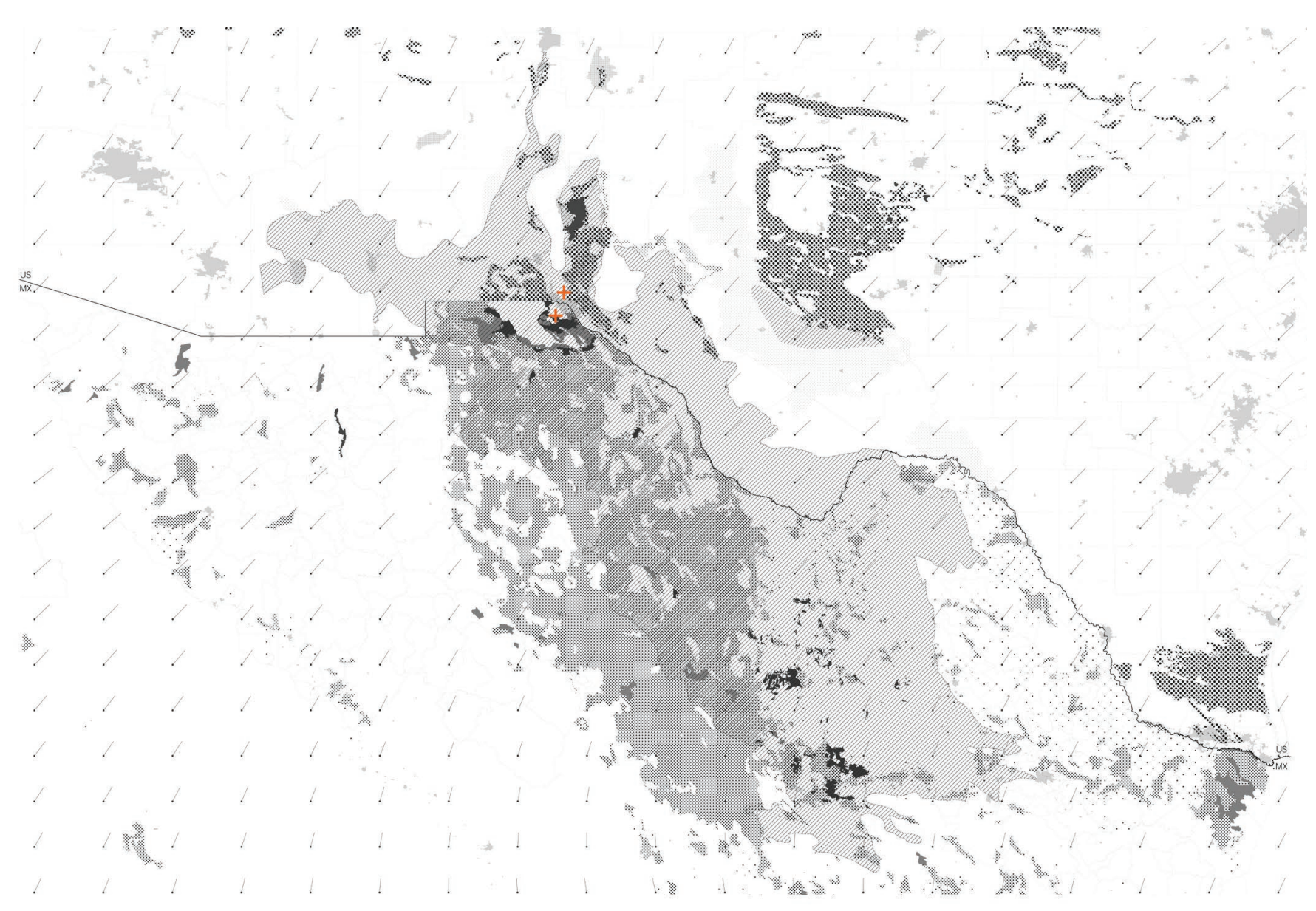

Figure 4. Airborne particulate origin sites, a geospatial database of all particulate matter types in the Chihuahuan Desert. Copyright AGENCY Architecture LLC.

including rural-urban migration, cross-border migration, peripheral urban development, informal construction, unregulated international commerce, and ongoing desertification. Airborne dust and windblown sand inundates the region, infiltrating inhabitants' respiratory tracts, and causing significant threats to health, safety, and life. Residents in El Paso have a $42 \%$ chance of encountering detrimental blowing dust on any given day, though the extent and location of these harmful 'dust events' are rarely detectable to the casual observer.

The project is designed to render the impact of airborne material visible and accessible, and to visually represent this sometimes-invisible material. An array of custom, low-cost air particulate sensors is installed in two low-resource communities across the US/Mexico border divide to provide a real-time, cross-border, citizen-sensing network. The online visualizations compile near-real-time air quality data from the network, offering the previously unavailable data to the afflicted communities as a resource through which to understand and enact policy change. Of equal importance to the information dissemination is the disciplinary development of a precise representation method that encompasses both the expansive scale of desert wind and the finite concentration of particulate matter it thrusts throughout the vast territory. At the territorial scale, the data registers onto a geospecific cartography of the Chihuahuan Desert, and ultimately informs a typological prototype for the housing of the sensor which transmits this data (figure 6). This representational method tracks particulate movements of the region to support binational conversations concerning unique material resources in an occupied desert, and its implications for air quality and public health.

The El Paso - Ciudad Juarez region is uniquely positioned as a shared atmosphere, the ground of which is highly regulated. While the securocratic apparatus controls the binational movement of bodies and products, its systems are unable (or unwilling) to register the contents of airborne particles moving freely between the two nations. Trapped in the valley, between the Franklin Mountains in the U.S. and the Juarez Sierras in Mexico, is a continuous cloud that spans the two cities across the border. The air is actively shared, along with its contents. Particulate matter is often confined close to the ground due to temperature inversions, which occur nocturnally and often. In the dry desert, at a considerable altitude of 3,700 feet above sea level, the diurnal temperature swings in the summer can reach up to 70 degrees Farenheit, 


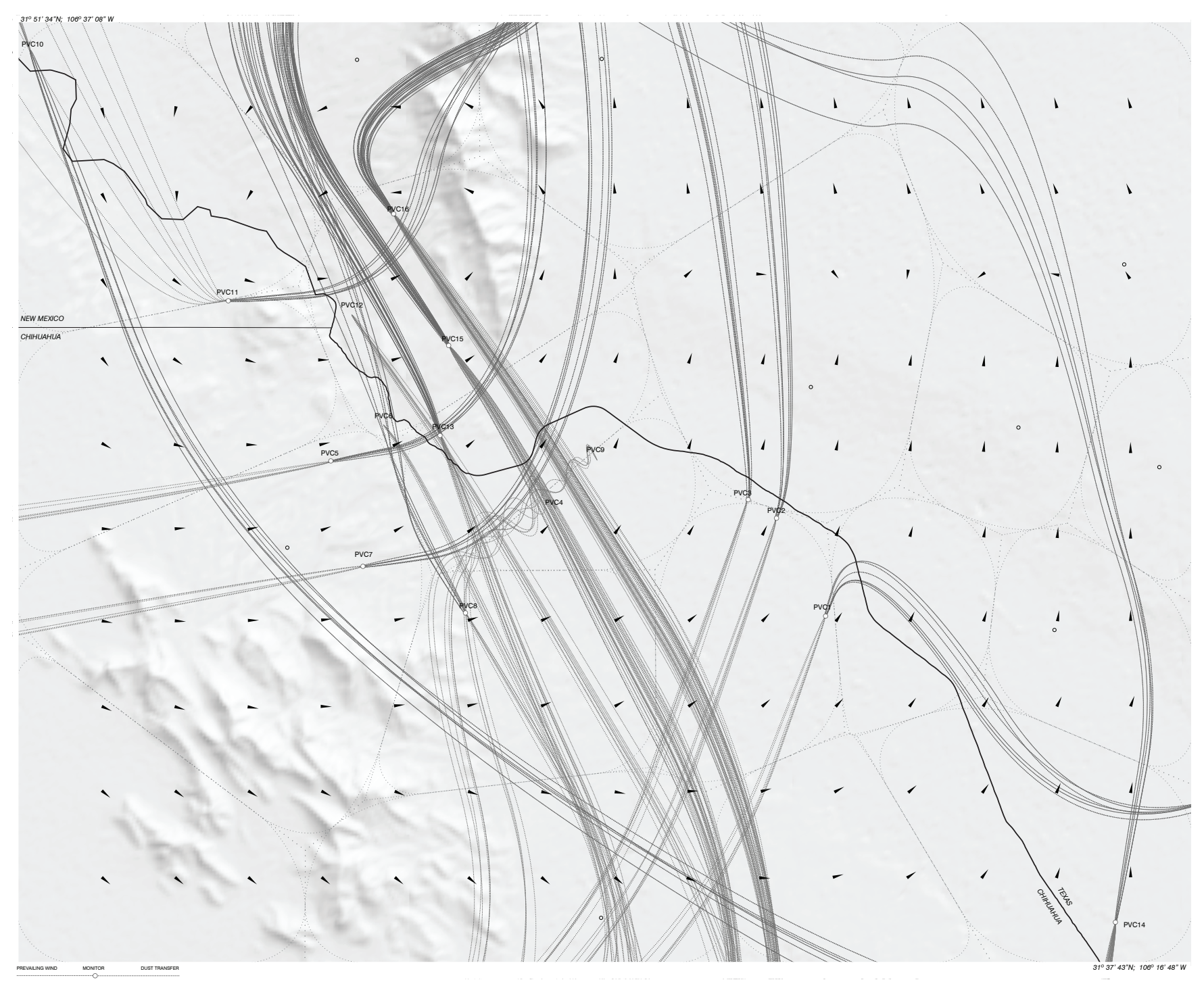

Figure 5. Dust Transfer Corridors - January midday winds. Copyright AGENCY Architecture LLC.
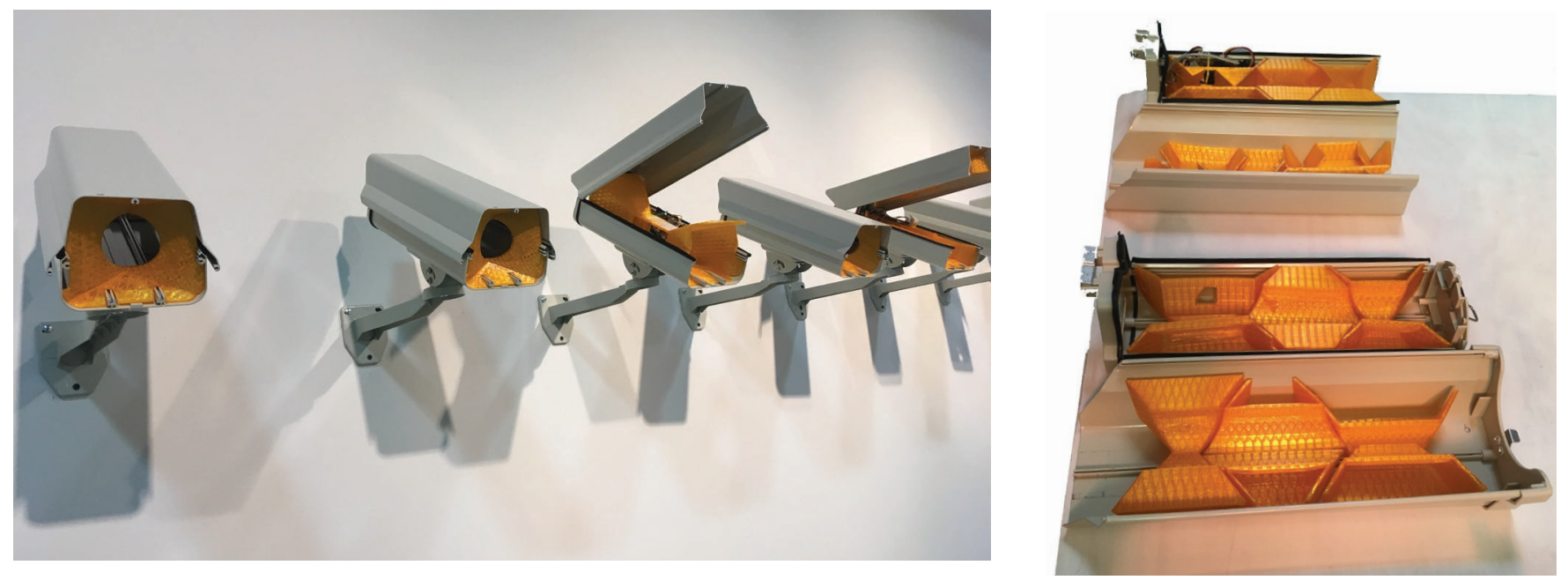

Figure 6. Hacked camera housings become dust sensor packaging. Copyright AGENCY Architecture LLC. 
which create the stratification of cold and warm air of the inversions. ${ }^{3}$ As warm air traps cold air near the earth's surface, dust, humidity, and other particulates are trapped in a swirling cloud without a possibility of releasing into the atmosphere above (figure 1).

As each country governs air quality differently, their indeces (AQI) trigger dissimilar pollution regulations, which become unenforceable in such proximity to the border. The atmosphere's resistance to comply with the political border renders it impossible to control, as it evades detection and detention. This resistance creates a nebulous physicality of the border, where the singular line is thickened generating a laissez-faire zone of extralegal pollution practices. The density of Juarez owes much of its development to the establishment of the Free Economic Zone of the Maquiladora industry. As low-wage jobs were created, the city saw an unprecedented growth expanding across the desert, mostly in self-settled and built neighborhoods, without proper infrastructural support from the multinational corporations or local government. Historically, factories and smelters would increase production when wind directions carried polluted air across the border, ${ }^{4}$ effectively exporting their unwanted dust. The condition of shifting wind patterns and microclimates along the border, and its use as an extralegal carrier, creates a challenging context for Nephelometry, which seeks to trace a gaseous landscape and to pin down its origins, as it were.

\section{DRAWN ACROSS BORDERS}

Nephelometry transcribes a shared aerial environment across national boundaries. The project documents the scattered territory of airborne particulate through a series of experiments in collective drawing. The procedural visualizations draw information gathered by individuals on both sides of the border in real time, while the lungs of the citizens draw-in the dust of the territory. Dust is an unseen threat. It evades detection as it crosses the border daily. The drawings register each sensor location as a singular emitter of information gathered by its hosts, and together, many households ping their personal data onto a digital canvas that collects and illustrates them as a unified field. While dust affects human health uniquely, the overall image of its trajectory emerges as a shared entity throughout the binational territory at large.

Regional air quality monitoring stations measure at the territorial scale and their data does not focus on hyper-local nuances or small dust events, which happen with speed and unpredictability. The ubiquitous infrastructures of monitoring and surveillance paradoxically focus on trends rather than events, in a context where the latter has the power to alter human life and safety in a matter of minutes. The physical manifestation of the project highlights these gaps in the surveillance and infrastructural system. CCTV extremities, infrared imaging, and thermal sensing gather and transmit information in one direction only, towards hierarchical opacity and control. Instead, the project hacks these now-routine objects in order to gather information for dissemination to a larger public. Camera housings are emptied and outfitted with custom-designed flexible inserts (figure 6) that house a bundle combination of dust sensor, rechargeable battery, GPS locator, blue tooth transmitter, solar panel, and main board. Iterating through various aerodynamic function requirements, the 3D printed inserts are designed to hold sensor components while formally registering and accommodating specific changes in the combination of air movement and sunlight throughout the desert day. The resultant taxonomy of these objects indexes a close relationship between the required form of the infrastructure of surveillance, the digitally fabricated design exercise, and the functionality of a measuring device, in order to reverse the direction of surveillance and monitoring in the border region.

Acknowledgements: Nephelometry Project Team: Ersela Kripa, Assistant Professor - TTU College of Architecture - El Paso, Partner at AGENCY Architecture LLC, Stephen Mueller, Faculty at TTU College of Architecture - El Paso, Partner at AGENCY Architecture LLC, Mary O'Malley - data visualization, Irving Cueller - TTU College of Architecture student, dust sensor maintenance, and Sergio Ramos - tech support. Project Support: The Rubin Center for Visual Arts at UTEP, New Cities Future Ruins - Gavin Kroeber, Texas Tech College of Architecture, Future+ and Design Trust Hong Kong, Handshake, SEEED, and Fab Lab El Paso.

\section{ENDNOTES}

1 See Joseph A. Amato, Dust, A History Of The Small \& The Invisible (Berkeley: University of California Press, 2000).

2 For an in-depth discussion of sand and desert material, see Michael Welland, Sand, The Never-Ending Story (Berkeley: University of California Press, 2009).

3 Encyclopaedia Britannica, "Temperature Inversion" entry.

4 John Burnett, "A Toxic Century: Mining Giant Must Clean Up Mess," NPR, February 4, 2010. https://www.npr.org/templates/story/story. php?storyld=122779177.

5 See David Campany, a Handful of Dust (Paris: Le Bal/Mack, 2015). 